\title{
Variation in Anemone apennina, L., and Clematis vitalba, L., with Special Reference to Trimery and Abortion.
}

\author{
BY \\ E. J. SALISBURY, D.Sc., F.L.S. \\ With nine Figures and two Tables in the Text.
}

In the present paper further data are furnished in support of the views already put forward by the author (Salisbury, 1919), relative to the essential trimery of the Ranunculaceae and the variation in number of the constituent parts of the flower through fission or fusion.

\section{ANEMONE APENNINA, L.}

THIS species affords an interesting subject for comparison with Anemone segments is six with a range of from 4 to 12 (cf. Yule, 1902; Salisbury, 1919), here the commonest condition is about 16 perianth segments with a range, as exhibited in the 150 flowers dissected, of from 9 to 21 .

Of the three regions of the flower the perianth most commonly exhibits departure from the trimerous condition which was found in 34 per cent. of the specimens, a proportion that practically coincides with the mathematical probability.

A noteworthy feature in comparison with its congener is the different form of the variation 'curve'. In Fig. I the curves for the two species and Anemone hepatica are shown, based on the data of Johnson (1908), Yule, and the writer. It will be seen that the 'curves' for $A$. nemorosa and $A$. hepatica are strikingly similar in general character, whilst that of the former resembles very closely the curve for the perianth of Eranthis hyemalis (cf. Salisbury, 1.c., Fig. 4, p. 52, 1919). In all three cases the normal number of perianth segments is six, whilst in A. apennina, where the normal number is much higher, the mode is near the centre of the curve. In other words, whilst in $A$. apennina the tendency towards diminution is as great as that of multiplication where the normal perianth number is low, the tendency is almost entirely in the direction of increase.

That this association is a real one is indicated by the change in form of the variation curve for the perianth of Ranunculus bulbosus which de Vries attained (1893) by repeated selection. Curves based on de Vries' 
figures (cf. Fig. 2) show an asymmetrical form where the average of the strain was five petals but an almost symmetrical form in the selected strain where the average number was nine.

In the one hundred and fifty flowers whose parts were carefully dissected, the androecium consisted of from 48 to I I stamens, both limits, as those for the perianth, being multiples of three. The most frequent
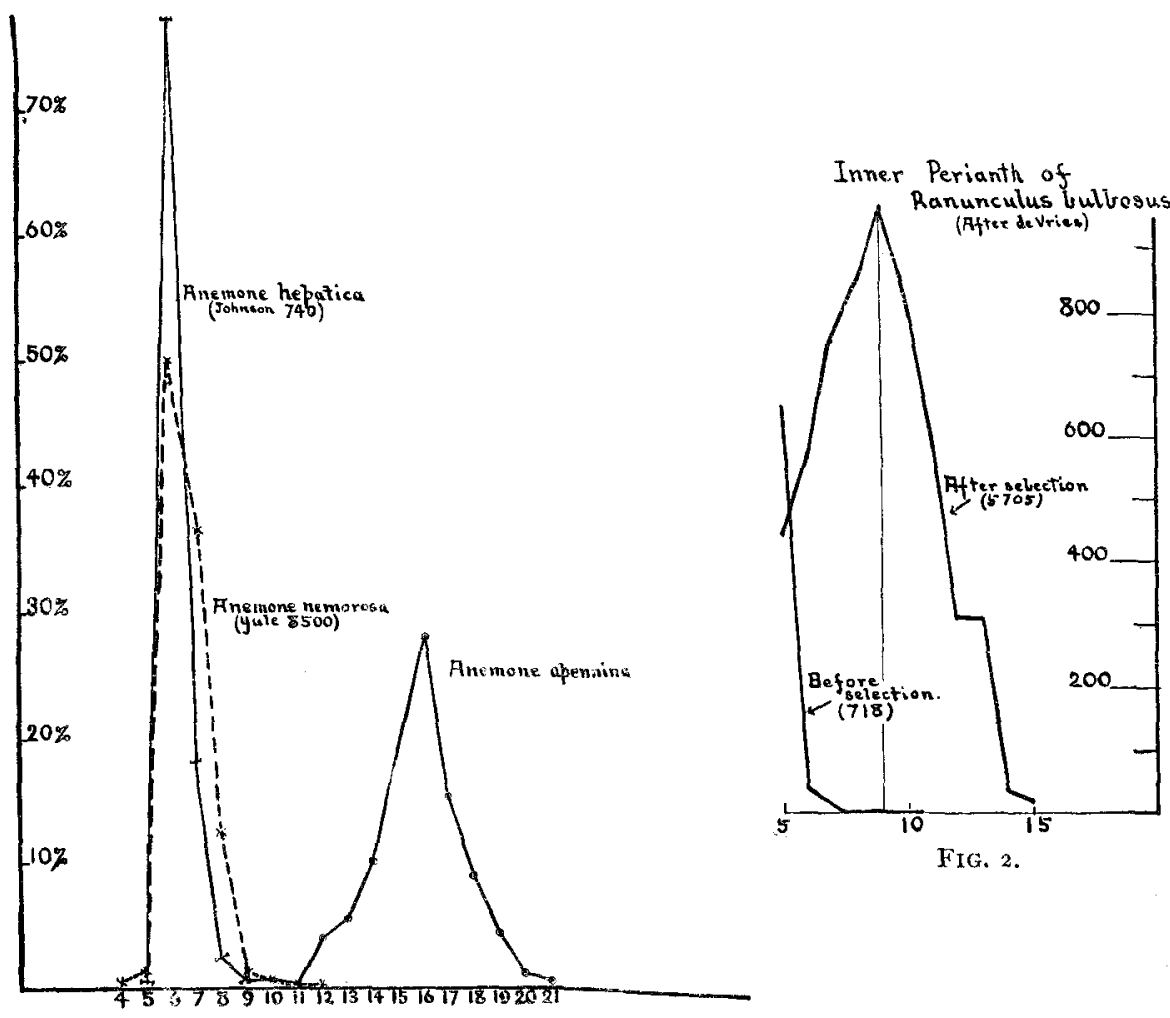

FIG. I.

conditions as shown by the 'curve' (Fig. 3) were 72,81 , and 87 . The marked periodicity of the 'curve' is obviously related to a succession of trimeric modes. In no less than 55.3 per cent. of the flowers examined the staminal number was some multiple of three.

Departure from the modes can here again be related to fission or fusion. Four flowers in which two anthers were present on a common filament exhibited a number of stamens which was a multiple of three $\left(6_{3}, 63,75\right.$, and 78 ) if the branching were ignored.

The essential trimery of the gynaeceum was even more pronounced, since the number of carpels was a multiple of three in 57.3 per cent. of the flowers, the most common conditions being 60,57 , and 63 carpels respectively. 
Not only does the variation 'curve' show the same periodicity with modes corresponding to multiples of three, but the decreasing prominence of these as we pass away from the primary mode is clearly exhibited (cf. Fig. 4). The range is from 27 to 87 , so that both in the gynaeceum and androecium the numbers compared with Ficaria verna (androecium ${ }^{5-63}$ and gynaeceum 8-5.5) are high. It may therefore be of significance that the 'curves' in that species are very asymmetrical, whilst here they are very much less so. Comparison within the same genus is, however, of greater value, and in the two species of Anemone (A.nemorosa and A. apennina) where
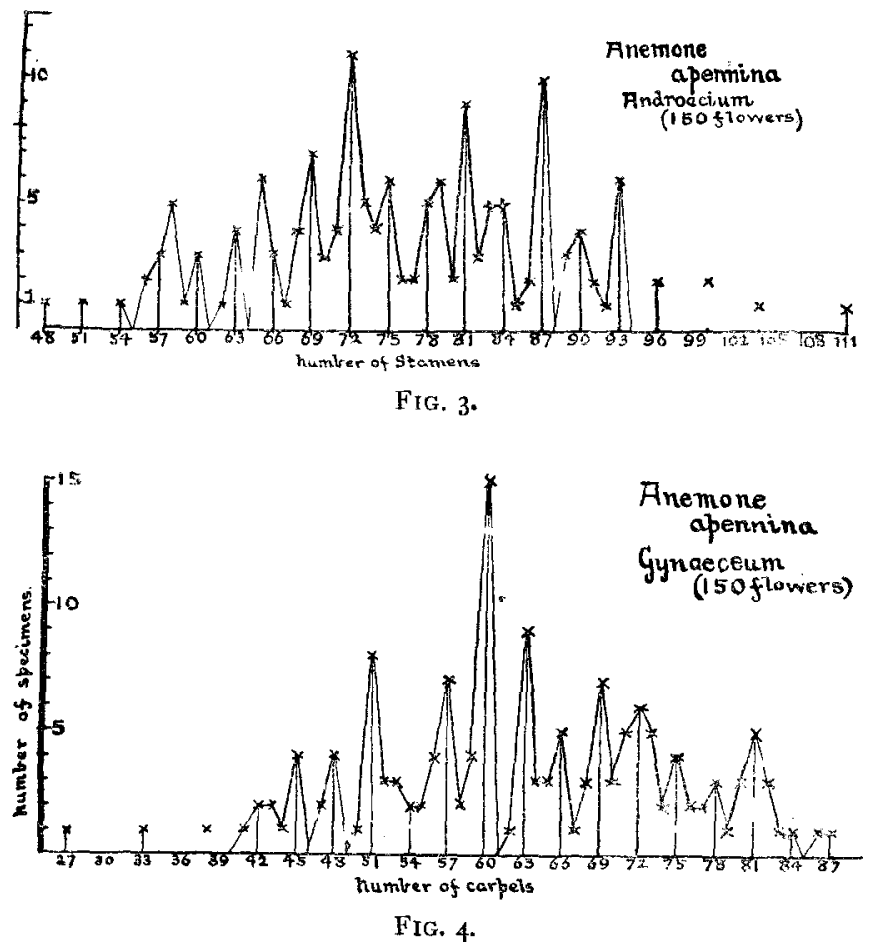

the average carpel number is so different the 'curves' show a marked contrast in respect to the degree of asymetry.

One instance of a carpel bearing two stigmas was observed, again suggesting fission as the cause of departure from the trimerous condition.

The large number of perianth segments in this species renders it particularly suited to a study of their origin. Five flowers exhibited petaloid stamens in which the anthers were represented to a more or less marked extent. Just as we cannot distinguish the stamens which have undergone complete fission, so too here we cannot recognize the completely petaloid stamens, since the latter do not in this genus bear any nectary. There is no doubt that both methods of origin contribute to produce 
variation of the perianth, but there are good reasons for regarding congenital fission, of the original segment rudiments, as the chief cause. The arrangement of the supernumerary parts is one ground for this view, but much more significant is the relation which the perianth number bears to the stamen number. From the following table it will be seen that the average number of stamens associated with a given number of perianth segments increases instead of decrcasing when the latter is large.
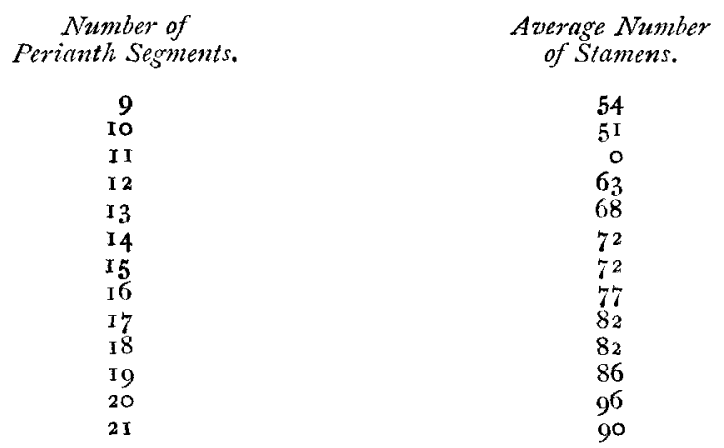

That a negative correlation obtains between perianth number and stamen number when the former is augmented by transformation of the latter has been shown in the case of Chelidonium majus by Karl Sax (1918), and conversely Bonnier noted (1889) that petal-less flowers of Atragene alpina always had more numerous stamens than normal petalled flowers.

It is of course patent from the work of Goebel (1905) and others (e.g. Saunders, 1917) that doubleness in its extreme form may involve transformation of stamens, which even in the same species (cf. Saunders, 1917) may or may not be accompanied by multiplication of parts. It is nevertheless important to guard our minds against the assumption that doubleness, in the popular use of the term, signifies a homogeneous group of phenomena, and still more, from the unsupported conclusion that the normal polymerous perianth is a phenomena of precisely the same nature as that exhibited in the extreme 'double' flowers of horticulture. In reference to the nonhomogeneity of the phenomenon of doubleness it may be pointed out that in two closely allied species of Dianthus Miss Saunders has shown that 'doubleness' is dominant in the one and recessive in the other-a fact difficult to reconcile with the presence and absence hypothesis except on the assumption that the 'doubleness' is of a different character in the two cases. We may also note that in the somewhat parallel phenomenon of fasciation White (1917) considers this morphological feature to be due to very varied causes (p. 490). 


\section{Clematis vitalba, L.}

The meristic variation in the gynaeceum of Clematis vitalba was investigated in $1,2,02$ specimens. As shown in Fig. 5, the curve exhibits a strikingly periodic form with maxima at multiples of three as in most of the genera and species already studied. But here the feature is more emphasized and the progressive decrease of the secondary modes is also well illustrated.

The importance of the secondary modes, and even the position of the primary mode, though always corresponding to a multiple of three, appear to vary with the individual and even in different parts of one and the same plant. Thus the specimens studied were obtained from three localities in the neighbourhood of Radlett. Those from the different localities gave

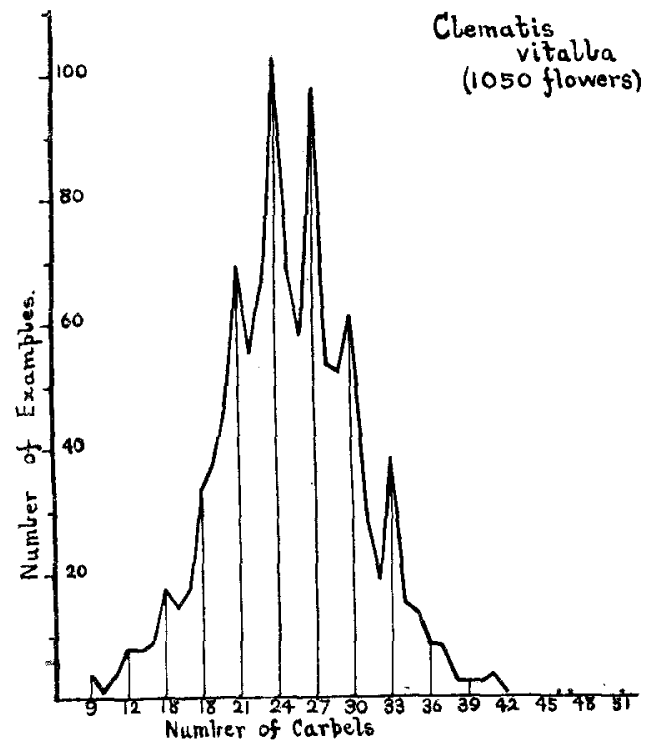

FIG. 5. very similar variation curves, but whilst from the one, gynaecea consisting of twenty-seven carpels preclominated, from the other two localities, gynaecea with twenty-four carpels were commonest. It is unlikely that this difference was due to any variation in the habitat conditions, which were apparently almost identical ; moreover, similar differences were noted when comparison was made of the different plants in the same locality.

Just as different primary modes may cha-

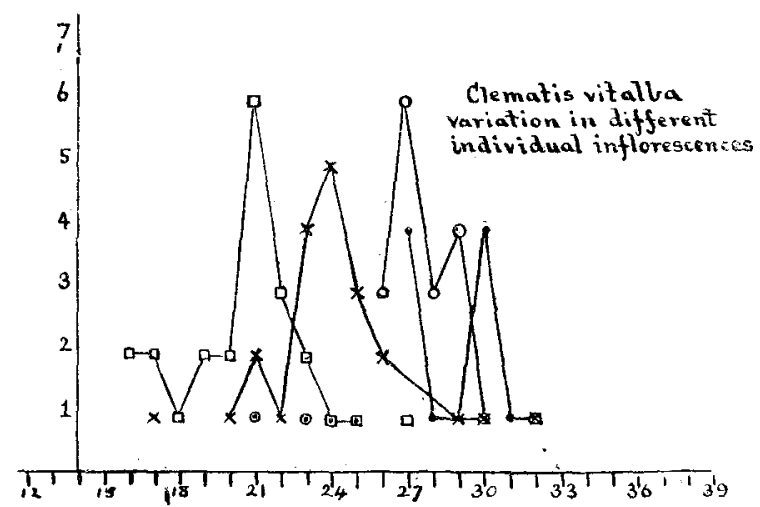

Fig. 6. racterize the various species of a genus, so too their relative prominence may vary with the individual. An interesting point, however, and one which is important in this connexion, is how far the individual is 
homogeneous in this respect. The data obtained from several hundred inflorescences were compared from this point of view, and the marked differences which those from the same branch may exhibit, both as regards variation range and the position of the mode, is illustrated by the curves for four separate inflorescences of the same plant reproduced in Fig. 6.

The marked trimery exhibited by the gynaeceum of this species is all the more interesting since the genus is characterized by a relatively primitive carpel in the sense that the functionless rudimentary ovules are retaimed (cf. Warming, 1913). One may hazard the suggestion that the marked trimery is associated with this gynaeceal conservatism. In respect

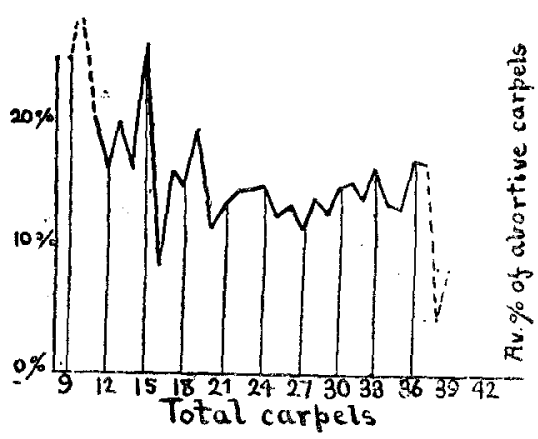

Fig. 7 .

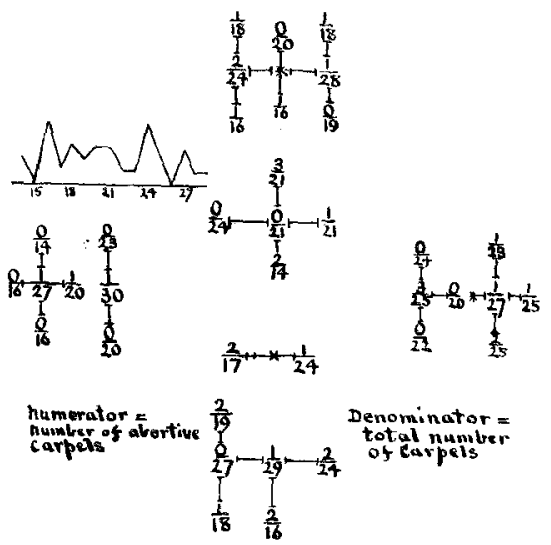

FIG. 8.

to this trimery the individual inflorescence bears much the same relation to the plant as a whole as does the 'pure line' to the homozygous strain from which it is selected. This tendency towards a segregation within the soma of the individual may be responsible for the fact that if one selects seed from flowers with a high number of perianth segments the offspring exhibits a higher average than do those raised from seeds produced in flowers of the same plant with a low perianth number. In Fig. 8 is shown a diagrammatic representation of a branch bearing a number of small inflorescences, and by its sides the variation curve for the gynaecea. It will be apparent that the range is relatively narrow, and in the different flowers of the individual inflorescence the total number of carpels exhibit a striking similarity. Here too, as indeed is generally the case, the terminal flower of a dichasium usually contains a greater number of carpels than the lateral flowers corresponding to it. Their relation is probably largely dependent on conditions of nutrition, the first-formed flower being naturally favoured in this respect. Exceptions are nevertheless by no means infrequent, and, especially in crowded inflorescences, the gynaeceum of the peripheral lateral 
flower may exhibit a numerical superiority not only over that of the corresponding interiorly placed lateral flower but also over that of the terminal member of its cyme.

Examples of branched carpels were found in eighteen fruit heads, or about $I .5$ per cent. Of course this represents under I per cent. of the total number of carpels examined, but in view of the fact that only where the process of fission is incomplete is the phenomenon recognizable we may conclude that such is probably by no means infrequent and may account for the variation about the different modes.

\section{Abortive Carpels in Clematis vitalba. Correlation between Fertile} AND ABortive CARPELS.

\begin{tabular}{|c|c|c|c|c|c|c|c|c|c|c|c|c|c|c|c|c|c|c|c|c|c|}
\hline \multirow{2}{*}{$\begin{array}{l}\text { Total } \\
\text { No. of } \\
\text { Carpels. }\end{array}$} & \multicolumn{21}{|c|}{ Number of Abortive Carpels. } \\
\hline & 0 & $\mathbf{I}$ & 2 & 3 & 4 & 5 & 6 & 7 & 8 & 9 & 10 & II & I 2 & I3 & 14 & ${ }^{\prime} 5$ & 16 & 17 & 18 & 19 & Totals. \\
\hline 9 & $\mathbf{r}$ & - & 2 & - & - & $I$ & - & - & - & - & - & - & - & - & - & - & - & - & - & - & 4 \\
\hline IO & - & - & - & - & - & - & I & - & - & - & - & $\sim$ & - & - & - & - & - & - & - & - & I \\
\hline I I & I & - & I & I & I & - & - & - & - & - & - & - & - & - & - & - & - & - & - & - & 4 \\
\hline I 2 & 3 & 2 & I & - & - & - & 2 & - & - & - & - & - & - & - & - & - & - & - & - & - & \\
\hline I 3 & I & 2 & $\mathbf{I}$ & I & 2 & - & I & - & - & - & - & - & - & - & - & - & - & - & - & - & 8 \\
\hline I4 & $\mathbf{r}$ & - & 5 & 2 & - & $\mathbf{r}$ & - & - & - & - & - & - & - & - & - & - & - & - & -- & - & 9 \\
\hline I5 & I & 3 & 2 & 2 & 2 & 3 & I & 3 & I & - & - & - & - & - & - & - & - & - & $\cdots$ & - & 18 \\
\hline 16 & 4 & 6 & 2 & 2 & - & I & - & - & - & - & - & - & - & - & - & - & - & - & - & - & I5 \\
\hline 17 & $\mathbf{3}$ & 4 & 4 & I & I & I & 2 & 2 & - & - & - & - & - & - & - & - & - & - & - & - & 18 \\
\hline I 8 & 5 & I 2 & 6 & 2 & 3 & - & - & $\mathbf{I}$ & 2 & 2 & 1 & - & - & - & - & - & - & - & - & - & 34 \\
\hline I9 & 4 & 5 & 5 & 7 & 6 & 4 & I & 2 & I & - & - & $\mathbf{I}$ & I & I & - & - & - & - & - & - & $3^{8}$ \\
\hline 20 & I I & 6 & 10 & 6 & 9 & 2 & - & 2 & $I$ & - & - & - & - & - & - & - & - & - & - & - & 47 \\
\hline 21 & 6 & I 8 & I4 & I I & 7 & 6 & 3 & I & I & I & I & I & - & - & - & - & - & - & - & - & 70 \\
\hline 22 & 7 & 8 & I3 & 8 & 6 & 4 & 2 & 3 & $\mathbf{I}$ & 3 & - & - & - & - & - & - & - & - & - & - & 55 \\
\hline 23 & 5 & 9 & I 5 & II & 7 & 3 & 9 & $I$ & 2 & 2 & I & I & - & - & - & - & - & - & - & I & 67 \\
\hline 24 & I 4 & 14 & 16 & ${ }^{\prime} 5$ & I 2 & IO & 5 & 2 & 6 & - & 3 & 2 & 2 & - & $\mathbf{I}$ & - & - & - & - & - & IO2 \\
\hline 25 & 9 & IO & 17 & I I & 5 & 5 & 3 & 4 & $\boldsymbol{2}$ & $\mathbf{I}$ & I & I & - & I & - & - & - & - & - & $\ldots$ & $7^{\circ}$ \\
\hline 26 & 6 & 8 & I3 & 9 & 8 & 2 & 2 & 2 & 3 & $\mathrm{I}$ & - & - & 2 & - & - & - & 1 & - & - & - & 57 \\
\hline 27 & 15 & 15 & 14 & 20 & IO & 7 & 6 & $I$ & $I$ & 4 & I & - & 2 & - & I & - & - & - & - & - & 97 \\
\hline 28 & 6 & 12 & 4 & 7 & 5 & 3 & 3 & 3 & 5 & - & $\mathbf{I}$ & I & - & $\mathbf{I}$ & - & - & - & $\mathrm{I}$ & - & - & $5^{2}$ \\
\hline 29 & 2 & I6 & 7 & 6 & 7 & 4 & 2 & I & 3 & $I$ & - & 1 & 2 & I & - & - & - & - & - & - & 53 \\
\hline 30 & 5 & 7 & 8 & 10 & 6 & 4 & 3 & 4 & - & 5 & - & & 2 & 2 & - & I & - & - & - & - & $5^{8}$ \\
\hline $3^{I}$ & I & 7 & 2 & ro & - & - & 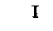 & 2 & I & 2 & 2 & - & - & I & I & I & - & -- & - & - & $\mathbf{3}^{\mathbf{I}}$ \\
\hline 32 & I & 3 & 4 & 2 & I & I & - & 2 & 2 & - & 3 & - & - & - & - & - & - & - & - & - & I9 \\
\hline 33 & I & 4 & 4 & 5 & 4 & 4 & 4 & I & 2 & 3 & 2 & 2 & I & - & - & - & - & I & - & - & $3^{8}$ \\
\hline 34 & 2 & I & 3 & $\mathbf{I}$ & 4 & & - & I & - & - & - & 1 & I & - & - & I & - & - & - & -- & 16 \\
\hline 35 & - & 2 & - & 3 & 2 & 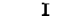 & I & 2 & I & I & - & - & - & - & - & - & - & - & - & - & $I_{3}$ \\
\hline $3^{6}$ & - & - & 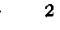 & I & I & I & I & - & - & I & I & - & - & - & - & $x$ & - & - & - & - & 9 \\
\hline 37 & - & - & I & 2 & 2 & - & - & I & - & I & I & - & - & - & - & I & - & - & - & - & 9 \\
\hline $3^{8}$ & - & 2 & - & I & - & - & - & - & - & - & - & - & - & - & - & - & - & - & - & - & 3 \\
\hline 39 & - & I & - & I & - & - & $\mathbf{I}$ & - & - & - & - & - & - & - & - & - & - & - & - & - & 3 \\
\hline 40 & - & - & I & - & - & - & - & - & 2 & -- & - & - & - & - & - & - & - & - & - & - & $\mathbf{5}$ \\
\hline $4^{I}$ & - & - & I & - & I & $i$ & - & I & - & - & - & - & - & - & - & - & - & - & - & - & 4 \\
\hline 42 & - & - & $I$ & - & - & - & - & - & - & - & - & - & - & - & - & - & - & - & - & - & I \\
\hline $4^{6}$ & - & - & $\cdots$ & - & - & - & - & - & - & $\rightarrow$ & $\mathbf{I}$ & - & - & - & - & - & - & - & - & - & 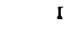 \\
\hline 47 & - & - & - & - & $\mathbf{I}$ & - & - & - & - & - & - & - & - & - & - & - & - & -- & - & -- & \\
\hline $5^{\mathrm{I}}$ & - & - & - & I & - & - & 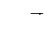 & - & - & - & - & - & - & - & - & - & $\ldots$ & - & - & - & I \\
\hline Totals & II 5 & 177 & 179 & 159 & $\mathrm{II}_{3}$ & 70 & 54 & $4^{2}$ & 37 & 28 & I9 & 12 & I 3 & 7 & $\mathfrak{3}$ & 5 & $\mathbf{I}$ & $a$ & 0 & $I$ & 1037 \\
\hline
\end{tabular}

Abortive achenes are of such frequent occurrence in Clematis vitalba that a relatively small proportion of the seed heads consist entirely of fertile fruits. The abortive achenes can be recognized by the fact that the body of 
the carpel is relatively flat in contrast with the robust swollen character of those which are fertile. Two types can, however, be recognized. In one the ovary remains quite small and the length of the style is only about 4 to $5 \mathrm{~mm}$. These doubtless represent carpels which have not been pollinated. It is significant of the effectiveness of the entomophilous pollination of this species that only an insignificant proportion of this type was encountered. The second type, representing about 98-99 per cent. of the abortive fruits, embraces those in which the ovary has undergone enlargement, though the absence of endosperm results in the flattened character already referred to. In these the style is almost, if not quite, as long as in fertile achenes. In the study of abortion in this plant we are not therefore dealing with the idiosyncrasies of a pollinating agent, but with some more subtle factor.

The number of abortive carpels was determined in $I, 040$ of the gynaecea examined, and a glance at the correlation table on p. II 3 shows that there is a definite tendency for the number of abortive carpels to increase with the increase in total number of carpels. The proportion nevertheless diminishes, as shown by the slight downward trend of the percentage curve (cf. Fig. 7).

As the more numerous carpels are generally associated with the better nourished flowers, the extent of abortion would seem to be also determined by conditions of nutrition and favourable development. In order to obtain evidence on this point the average percentage of abortive carpels in a number of terminal fruiting heads was compared with that of the corresponding laterals. The value of the former was found to be 11.7 per cent. and of the latter 13.6 per cent. That is to say, the proportion of carpels which abort is greater in the lateral flowers than in the terminal.

\section{Additional Note on Ficaria verna.}

Since the publication of the writer's previous paper in which the variations of this species were dealt with, several further papers on this species have come to his notice. Of these, the most important are those by F. Ludwig (1908), Prof. Macleod (1907), and A. A. Dallman (1915 and 1916). In the first of these a number of tables are furnished which show the correlation betwcen sepals and petals in Ficaria verna. The corresponding correlation coefficients were subsequently worked out by Miss Lee (1908) for the various localities from which the specimens were obtained and show a positive correlation in most cases which seems to preclude the acceptance of the transformation theory $(0.1928 \pm 0.0205 ; 0.1954 \pm 0.0203 ; 0.0188 \pm 0.0260$; and $0.2237 \pm 0.0203$ ). In the second paper Prof. Macleod gives correlation data for the number of stamens and pistils of 373 late flowers and 268 early flowers. From the figures there furnished the curves illustrated (Fig. 9) were constructed, and it will be noted that the androecia of the late flowers show two modes corresponding to fifteen and eighteen stamens respectively, 
whilst the early flowers exhibit a prominent mode at twenty-seven. In the 'curve' for the gynaecea of the early flowers no trimery is apparent, but the more numerous examples of late flowers show a clear tendency in this direction. Prof. Macleod's figures, therefore, though emphasizing the trimerous tendency, do not show the periodic grouping to so marked an extent as the specimens examined by the writer.

It may perhaps be well to emphasize the fact that in all the specimens dealt with in this investigation the parts have invariably been counted twice to avoid possible error, and wherever necessary examined under the dissecting microscope to ensure the inclusion, in the total, of aborted rudiments and the recognition of any precocious abscission. To avoid error from the latter cause such examination is particularly necessary where unopened buds are not exclusively employed.

In the last-named paper Mr. Dallman has collected data regarding the perianth of Ficaria verna from over 49,000 flowers derived from a number of widely separated localities. The results show that though the mode is the same in all cases the relative proportion of specimens show-
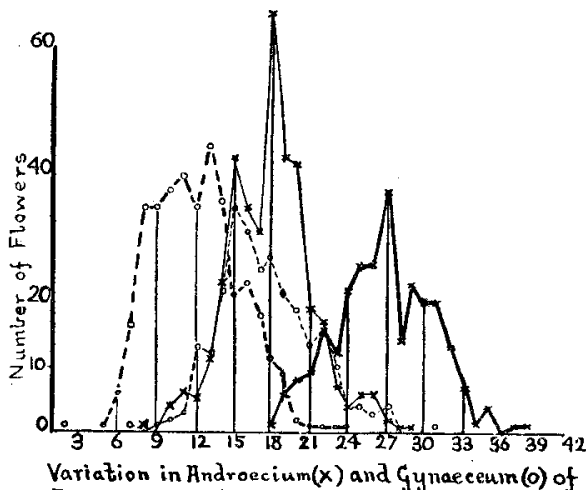
Ficaria verma (268 Early flowers 373 late flowers $\Rightarrow$ ) (From data collected by Prof. J. Mackeod of loc cit)

FIG. 9 . ing increase or decrease may vary with the locality or season. The range in sepal number observed was from $0-6$ and of petals from 4-ig. The latter figures are identical with those given by Babington (1834). In reference to the calyx Mr. Dallman expresses the doubt as to whether true asepaly occurs, and, indeed, in all the examples studied by the writer, in which there were apparently less than three sepals, this was found to be due to precocious abscission or petaloidy of one or more members. With respect to the corolla the upper limit in the present writer's specimens, viz. eleven, appears to be scldom exceeded, and the thrce examples cited by $\mathrm{Mr}$. Dallman with seventeen, eighteen, and nineteen petals respectively are admitted to have been the outcome of fasciation. 


\section{Salisbury.-Variation in Anemone apennina, L., SOC.}

\section{Bibliograpity.}

Babington, C. C. (1834): On the Supposed Generic Distinction of Ranunculus Ficaria of Linné. Mag. Nat. Hist., vol. vii, pp. 375-7.

Bonnier, G. (1889): Observations sur les Renonculacées de la Flore de France. Revue Gén. de Botanique.

Dallman, A. A. (1915): The Lesser Celandine. Lancashire and Cheshire Naturalist, vol, viii, pp. I80-7 and 201-7.

(1916): Further Notes on the Lesser Celandine, Ibid., pp. 2I5-22, 242-5, and $263-5$.

Goeber, K. (1905): Organography. English Ed. Oxford.

JoHnson, R. H. (1908): Variation in Syndesmon and Hepatica. Ohio Naturalist, vol. ix, No. 3, pp. 43 I -6.

LEE, A. (1908) : Note on Dr. Ludwig's paper. Biometrika, vol, i, pp. 316-I9.

Letghton, W. A. (1835): Ranunculus Ficaria. Mag. Nat. Hist., vol. viii, p. 280.

LUdwig, F. (1908): Variation : statistische Probleme und Materialien. Biometrika, vol. i.

MACLEON, J. (1907): Over de correlatie tusschen het aantal meeldraden en het aantal stampers bij het Speenkruid (R. Fïcaria).

Salisbury, E. J. (1919): Variation in Eranthis hyemalis, Ficaria verna, and other members of the Rantunculaceae, with Special Reference to Trimery and the Origin of the Perianth. Ann. Bot., vol. xxxiii, pp. 47-79.

SaUnders (1917): The Inheritance of Doubleness in Meconopsis, Althaea, and Dianthus. Journal of Genetics.

SAx, Karl (1915): The Inheritance of Doubleness in the Flowers of Chelidonium majus. Ibid., pp. $207-30 \%$.

DE VRIES, H. (1893): Les Demi-courbes Galtoniennes. Arch. Néerlandaises, t. xxviii, pp. 442-57.

Warming, E. (1913): Observations sur la valenr systématique de l'Ovule. Copenhagen.

WeLdon, W. F. R. (1908): Biometrika, vol. i, pp. I $25-8$.

White, O. E. (1917): Studies of Inheritance in Pisum. Proc. Amer. Phil. Soc., vol. lvi, pp. 487-588. 